\title{
RISE, CULTURAL EYES, RISE: CULTURALIZE!
}

\author{
By Robert V. Kozinets
}

I believe that there has never been a better time for scholars to undertake cultural research, or to begin to think about what it means to apply a cultural lens to the questions that face marketing and consumer researchers, as well as marketing practitioners. I appreciate this opportunity to explain what is happening in the field of culturally oriented research in consumer and marketing research, and then to expand upon it.

Let us first try to understand what we mean by a cultural understanding. What does it mean to say that we apply a cultural understanding to a consumption activity, to a consumer, to a marketing text, to a marketplace? We can consider consumer culture to be an interconnected system of commercially produced images, texts, and objects that people use. Consumers use these commercial productions by coming up with practices, or significant behaviors, identities, rituals, and meanings. As well, people use these commercial productions in order to make collective sense of their environments and to orient their own experiences and, even more dramatically, their lives.

From the standpoint of our understanding, of our sense of meaning, culture is everything. If we do not understand a language, words are gibberish and the grasping of lasting meaning is impossible. If we do not grasp the rules of a culture, we are helpless, and useless; no matter what our intelligence used to be, in that culture we are dolts. Anthropologist Clifford Geertz explained culture as a type of spider's web of significance and meaning spun collectively by human beings and yet in which we all hang suspended together. If we understand each other, it is because we both hang suspended in the strands of the same web.

There are parallel processes at work in the world of consumption. Every consumer ritual has its guiding principles, as Sidney Levy, Grant McCracken, and Dennis Rook have emphasized. Consumer anthropologists

Mercati e Competitività n. 2, 2012 
set themselves the task of following and understanding the cultural strands of the social webs in which consumption occurs. Thus to interrogate consumption in this cultural way is this way is to understand the role of consumption in some of the deepest shared elements of human groups and their societies: consumption as a source of power, as laden with meaning, as taught and learned, as habitual ritual, as natural and everyday, as special and deeply significant.

If we can consider culture to be socially patterned human thought and action, then a cultural examination of consumption holds the potential to reveal much about what links our contemporary society, with its dominant corporate and marketplace institutions, together. When scholars study particular subcultures or general aspects of consumer collectives or even of consumer society, they must focus their attention on a range of distinctive cultural elements that reveal powerful insights about who we are as a civilization. Consumer anthropologists encounter extant symbol systems and new languages. They seek out rituals, the repeated patterns of behavior that are saturated with meaning. They hunt and preserve stories of passion, networks of narratives, and vast universes of shared narratives. The consumer anthropologist queries the value of value systems and sees social structures emerge with related relations of dominance and submission.

Cultural insights are built on these foundations. Cultural analysts treat every aspect of consumption as a language, from a package design to a hand movement, from a gesture or a turn of phrase to the momentary facial expression that comes when an advertisement is shown, to the place in the home where a product is stored. Everything that happens surrounding a consumption activity is data that can be collected. Everything that happens surrounding a consumption activity is a language to be translated, a puzzle to be solved, a cryptic message to be decoded.

If stories and narratives are told and passed around, it is the cultural analyst's sacred task to listen, to compare, to unwind, and to understand. If hierarchies are evident, the cultural analyst must see status and striving as sources of increased insight. Structures, systems, symbols, values, routines, and meanings: all of these are vital cultural elements to which the analyst must be attuned. Consumer ethnography is based in this. It is insight-generation transpiring in the frictional space between observation, participation, thoughts, actions, language, and representations. Consumer ethnography is nothing more and nothing less than pattern recognition that takes place under conditions of the highest complexity we can imagine or manifest: the lived cultural world of contemporary consumer society.

For example, consider that a mobile phone provider wishes to understand the world of mobile phone users. To take a cultural approach means that the researcher must understand the world of the mobile phone user in context, as it occurs naturally. It will mean interviews with users asking 
them about their phone, about its uses and significance, about the meanings that attach to mobility, about the various images that attach to different phone users - from traditional Nokia diehards, to boring Apple followers, to Android geeks, to cutting edge Samsung innovators. It may mean observing phone users as they use their phones, noting how they decorate and customize their phone, where they keep it on their body, where they put it when they are at home and when they go to other locations, how they use it when they are in restaurants and at the family dinner table, and at work. Some of this observational work may be videotaped. Some of it may be captured in fieldnotes and jottings. A cultural approach might also involve the analysis of ads for mobile phones, an analysis of the different types of images attaching to mobile phone, an examination of the history of the mobile phone and its changing meanings. Conducting cultural research means conducting research that seeks deep understanding of consumption, brands, products, categories, and even contemporary culture itself.

I wrote earlier in this editorial that the optimal time is now - that there may never be a better time for scholars new and old to undertake cultural research, or to begin to a cultural lens to marketing questions and problems both theoretical and industrial. There are several reasons for this.

I believe that our complex contemporary environment offers us a huge and ever-expanding set of fascinating areas and phenomena that demand the sorts of richly contextualized understandings that cultural inquiry brings. Consider, for example, social media and the Internet. Over the past 17 years, I have been introducing and developing the approach of netnography, an adaptation of ethnography particularly suited to the contingencies of computer-mediated communications. In that 17 year period, I have seen an incredible expansion of the space of what we used to call "virtual communities," changing from web forums and crude text-based games and chat rooms populated by a few thousand innovative users from around the world to the sophisticated multi-million population and multi-billion dollar social networking sites and microblogs of today, as well as the geo-locational and mobile community building tools. As consumption increasingly takes place in cultural environments such as these, consumer insights must increasingly turn to them in order to understand the complete reality of consumers today. Consider also not only that social media as a cultural space is constantly growing and evolving, but also that consumer culture itself is highly mutable and dynamic, and also that consumer culture is expanding and mutating around the globe.

Next, we must acknowledge that not only are cultural approaches increasingly in demand in te corporate sector, but that they have become increasingly present within academia. There are now more outlets for highquality cultural and marketing-oriented consumer research than ever before. The Journal of Marketing, the Journal of Consumer Research, the 
Journal of Consumer Psychology, the Journal of the Academy of Marketing Science, the Journal of Retailing, the Journal of Business Research and many other general marketing and management journals are open to culturally oriented submissions and regularly publish high-quality work in this domain. In addition, specialty journals such as the Journal of Consumer Culture, Consumption, Markets, and Culture, and the Journal of Contemporary Ethnography are devoted to work that specifically examines the contemporary world - whether marketing-oriented or not - through a dedicated cultural lens.

Meanwhile, the institutionalization and legitimizing of the field of cultural inquiry in consumer and marketing research has gained impressive momentum over the past decade. Russ Belk has published a very helpful volume of work on the conduct of qualitative marketing research, and Russ, Eileen Fischer and I recently wrote a new how-to guidebook about qualitative marketing and consumer research for Sage. There are now a variety of different workshops held relatively around the world to teach Ph.D. students these techniques and to bring them access to some of the top scholars in the field to learn from. In addition, there is now a large, growing, and influential annual conference dedicated to Consumer Culture Theory. Doctoral dissertations in the area are increasing, and the influence of these scholars is on the rise. This is not to say that there are no lingering institutional barriers from bygone and biased days that held out against the "new" forms of anthropological and sociological research in the marketing and consumer research field. However, I do believe that the momentum of cultural insight and cultural research is now considerable and growing stronger every year.

Finally, I think that, as with all human activities and within all industrious activities of human beings, innovation and creativity are vital to preserve the vivacious spirit of life. In the field of culturally oriented consumer and marketing research, this flame of creativity has been allowed to flourish. Arguably, there are some interesting and innovative activities occurring across all of the various subfields of consumer and marketing research. But the cultural approach has spawned some of the richest, most heavily-cited, and most influential theories coming out of the marketing field: from those on cultural transfer of meaning, to relationship theories, to those of extended self, the sacred and profane, to classification of social media and online community members, subcultures of consumption, and brand communities. New and important methods have been developed. Poetry has become an important and increasingly legitimate way to represent certain "resonant" and "evocative" types of consumption knowledge. Videography was pioneered and has developed into a subbranch of consumer research in which the representation of consumer realities on film is paramount. All of these theories and methods have at their core the com- 
mon quest to maintain the inherent richness of the cultural consumption context in their research and their theorization.

From within this context comes this momentum, emerges this set of insights, proceeds the freedom to be creative and to explore the marketized and marketizing contemporary world. From this world and this scientific pursuit comes the imperative to seek to understand the world of contemporary consumers in all of its rich complexity, to see the world through cultural eye. From this context comes the imperative not to reduce the world unduly, not to place blinders upon understanding, not to choke out the rich voice of reality.

From this context comes the commonplace call, spoken in a lucid, plain, and honest voice: culturalize...culturalize...culturalize... 